
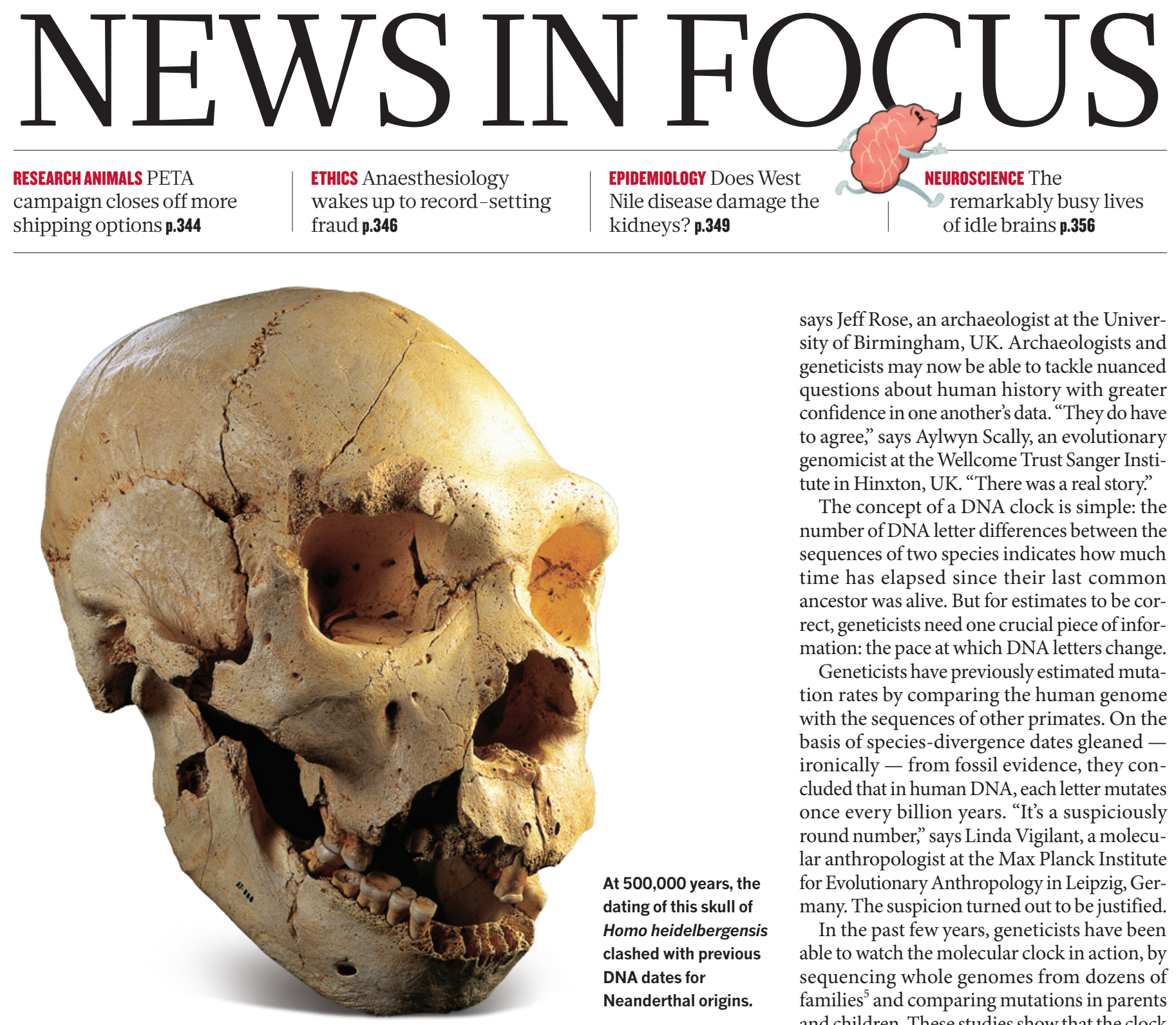

At 500,000 years, the dating of this skull of Homo heidelbergensis clashed with previous DNA dates for Neanderthal origins.

\title{
ANTHROPOLOGY
}

\section{Studies slow the human DNA clock}

\section{Revised estimates of mutation rates bring genetic accounts of human prehistory into line with archaeological data.}

\section{BY EWEN CALLAWAY}

$\mathrm{T}$ The story of human ancestors used to be writ only in bones and tools, but since the 1960s DNA has given its own version of events. Some results were revelatory, such as when DNA studies showed that all modern humans descended from ancestors who lived in Africa more than 100,000 years ago. Others were baffling, suggesting that key events in human evolution happened at times that flatly contradicted the archaeology.

Now archaeologists and geneticists are beginning to tell the same story, thanks to improved estimates of DNA's mutation rate - the molecular clock that underpins genetic dating ${ }^{1-4}$. "It's incredibly vindicating to finally have some reconciliation between genetics and archaeology," says Jeff Rose, an archaeologist at the University of Birmingham, UK. Archaeologists and geneticists may now be able to tackle nuanced questions about human history with greater confidence in one another's data. "They do have to agree," says Aylwyn Scally, an evolutionary genomicist at the Wellcome Trust Sanger Institute in Hinxton, UK. "There was a real story."

The concept of a DNA clock is simple: the number of DNA letter differences between the sequences of two species indicates how much time has elapsed since their last common ancestor was alive. But for estimates to be correct, geneticists need one crucial piece of information: the pace at which DNA letters change.

Geneticists have previously estimated mutation rates by comparing the human genome with the sequences of other primates. On the basis of species-divergence dates gleaned ironically - from fossil evidence, they concluded that in human DNA, each letter mutates once every billion years. "It's a suspiciously round number," says Linda Vigilant, a molecular anthropologist at the Max Planck Institute for Evolutionary Anthropology in Leipzig, Germany. The suspicion turned out to be justified.

In the past few years, geneticists have been able to watch the molecular clock in action, by sequencing whole genomes from dozens of families ${ }^{5}$ and comparing mutations in parents and children. These studies show that the clock ticks at perhaps half the rate of previous estimates, says Scally.

In a review published on 11 September ${ }^{1}$, Scally and his colleague Richard Durbin used the slower rates to reevaluate the timing of key splits in human evolution. "If the mutation rate is halved, then all the dates you estimate double," says Scally. "That seems like quite a radical change." Yet the latest molecular dates mesh much better with key archaeological dates.

Take the 400,000-600,000-year-old Sima de Los Huesos site in Atapuerca, Spain, which yielded bones attributed to Homo heidelbergensis, the direct ancestors of Neanderthals. Genetic studies have suggested that earlier ancestors of Neanderthals split from the branch leading to modern humans much more recently, just 270,000-435,000 years ago. A slowed molec-

\section{$\rightarrow$ NATURE.COM}

For a special issue on ancient human migrations, visit: go.nature.com/jcunxr ular clock pushes this back to a more comfortable 600,000 years ago (see 'Better agreement over the human story')

A slower molecular 


\section{BETTER AGREEMENT OVER THE HUMAN STORY}

Dates estimated from DNA evidence conflicted with those from fossil sites that document key events in prehistory, but dates gained using a slower DNA clock are resolving some conflicts.

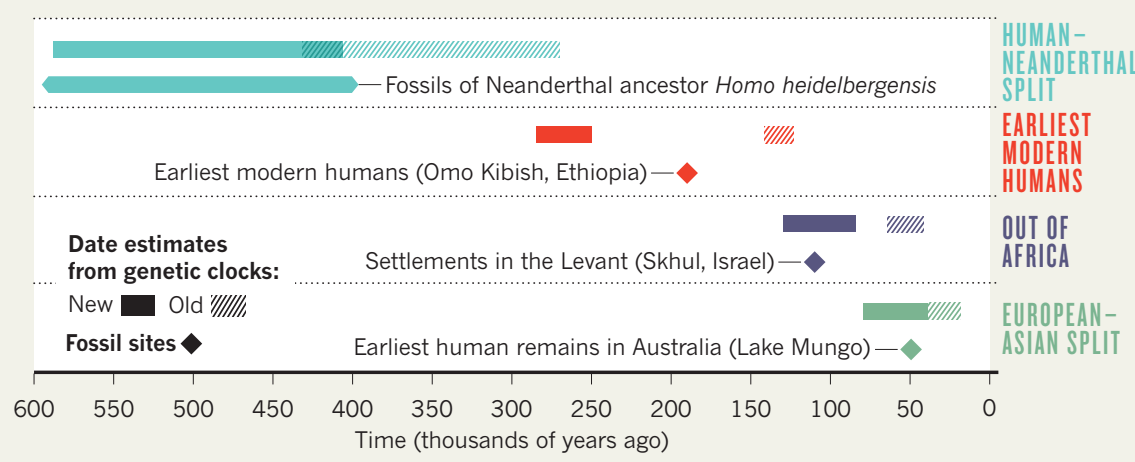

- clock could also force scientists to re-think the timing of later turning points in prehistory, including the migration of modern humans out of Africa. Genetic studies of humans around the world have suggested that the ancestors of Europeans and Asians left Africa about 60,000 years ago. That date caused many to conclude that 100,000-year-old human fossils discovered in Israel represented a deadend migration rather than the beginning of a global exodus, says Scally. Scally's calculations put "out of Africa" closer to 120,000 years ago, suggesting that the Israeli sites represent a launching pad for the spread of humans into Asia and Europe.

The latest genetic dates also fit with several sites in the Middle East that contain tools apparently made by modern humans but dating to around 100,000 years ago. At that time, sea levels between Africa and the Arabian Peninsula were lower than they are now, and a wetter climate would have made the peninsula lush and habitable, perhaps beckoning modern humans out of Africa. Rose, who works one such site, in Oman, says that he "has been over the moon" since reading Scally and Durbin's paper.

The revised molecular clock may also help to settle a debate over whether humans ventured further into Asia more than 60,000 years ago, says Michael Petraglia, an archaeologist at the University of Oxford, UK, who favours an early date.

Although a slowed molecular clock may harmonize the story of human evolution, it does strange things when applied further back in time, says David Reich, an evolutionary geneticist at Harvard Medical School in Boston, Massachusetts. "You can't have it both ways."

For instance, the slowest proposed mutation rate puts the common ancestor of humans and orang-utans at 40 million years ago, he says: more than 20 million years before dates derived from abundant fossil evidence. This very slow clock has the common ancestor of monkeys and humans co-existing with the last dinosaurs. "It gets very complicated," deadpans Reich.

Some researchers, including Scally, have proposed that the mutation rate may have slowed over the past 15 million years, thereby accounting for such discrepancies. Fossil evidence suggests that ancestral apes were smaller than living ones, and small animals tend to reproduce more quickly, speeding the mutation rate.

Little concrete evidence supports this idea, says Reich. He agrees that the molecular clock must be slower than was thought, but says that the question is how slow. "My strong view right now is that the true value of the human mutation rate is an open question." -

1. Scally, A. \& Durbin, R. Nature Rev. Genet. 13, 745-753 (2012).

2. Langergraber, K. E. et al. Proc. Natl Acad. Sci. USA http://dx.doi.org/10.1073/pnas.1211740109 (2012).

3. Hawks, J. Proc. Natl Acad. Sci. USA http://dx.doi. org/10.1073/pnas.1212718109 (2012).

4. Sun, J. X. et al. Nature Genet. http://dx.doi. org/10.1038/ng.2398 (2012).

5. Kong, A. et al. Nature 488, 471-475 (2012).

\section{Lab-animal flights squeezed}

\section{Two biggest cargo carriers affirm that they will not ship mammals and non-human primates, as activist pressure mounts to stop research-animal airlifts.}

\section{BY MEREDITH WADMAN}

$\mathrm{F}$ or researchers who rely on lab animals shipped from distant sources, and for the companies that breed them, the options are narrowing again. This week, People for the Ethical Treatment of Animals (PETA) will announce that it has obtained written assurances from the world's two largest aircargo carriers, FedEx and UPS, that they will not transport mammals for laboratory use. UPS says that it is also planning to further "restrict" an exemption that allows the transport of amphibians, fish, insects and other non-mammals.

Neither company currently ships large numbers of lab animals. But PETA, an activist group based in Norfolk, Virginia, sought the carriers' written assurances as a way to foreclose alternatives for lab-animal breeders and their customers, who are increasingly being confronted with bans on transport by passenger airlines. "FedEx and UPS were not transporting many or any animals, but we felt it was crucial to go to them and discuss this as we knew that facilities trying to send non-human primates and other species would be going to them soon, as more and more passenger airlines refused to do business with them," says Kathy Guillermo, PETA's senior vice-president for laboratory investigations.

The commitments will have a direct impact on some researchers. "I am deeply concerned," says Darcy Kelley, a neurobiologist at Columbia
University in New York City, who studies neural and muscular systems involved in vocal communication in the frog Xenopus. The supply companies that Kelley uses - Nasco in Fort Atkinson, Wisconsin; Xenopus One in Dexter, Michigan; and Xenopus Express of Brooksville, Florida - all ship the amphibians by air with UPS for next-day delivery. Losing access to the frogs because of shipping hurdles "would set my research back years", says Kelley. "It takes Xenopus females two years to get to sexual maturity. And maintaining an animal colony is a very expensive proposition."

For those who study mammals, the FedEx and UPS policies may have little immediate impact. The two companies are not used to ship non-human primates internationally, says 